\title{
A study of maternal and perinatal outcome in cases of HELLP and partial HELLP syndrome
}

\section{Kanchan Durugkar*, Himadri Bal, Sharda Agrawal}

Department of Obstetrics and Gynecology, D. Y. Patil Medical College, Pune, Maharashtra, India

Received: 26 September 2017

Accepted: 30 October 2017

\section{*Correspondence:}

Dr. Kanchan Durugkar,

E-mail: kanchan3077@gmail.com

Copyright: (c) the author(s), publisher and licensee Medip Academy. This is an open-access article distributed under the terms of the Creative Commons Attribution Non-Commercial License, which permits unrestricted non-commercial use, distribution, and reproduction in any medium, provided the original work is properly cited.

\begin{abstract}
Background: The HELLP syndrome is a serious complication in pregnancy characterized by haemolysis, elevated liver enzymes and low platelet count occurring in 0.5 to $0.9 \%$ of all pregnancies and in $10-20 \%$ of cases with severe preeclampsia. The objective of the present prospective study is to study on incidence, diagnosis, and variable presentations of HELLP syndrome in preeclampsia to analyse the severity and complications, as it is associated with maternal, perinatal morbidity and mortality. HELLP syndrome is difficult to diagnose when it presents with atypical clinical features.

Methods: In the prospective study of 300 admitted cases with more than 20 weeks of gestation, were having preeclampsia. The selected cases were analyzed clinically with relevant history, clinical data and detailed laboratory investigations made for better analyses of complications and outcome in HELLP syndrome.

Results: Under further clinical diagnosis of 300 cases of preeclampsia, 34 cases $(11.33 \%)$ were of HELLP Syndrome and $44(14.66 \%)$ cases were of partial HELLP syndrome. The present study shows $2.9 \%$ maternal mortality in HELLP and $4.5 \%$ in partial HELLP syndrome. Perinatal mortality was $17.6 \%$ with HELLP and $25 \%$ with partial HELLP.

Conclusions: The diagnosis of HELLP syndrome has been made as a severe variant and complication of severe preeclampsia and eclampsia. It needs early diagnosis, timely intervention to arrest further progress and complications like multi organ dysfunction, renal failure, DIC, abruption etc and to improve maternal and perinatal outcome.
\end{abstract}

Keywords: HELLP syndrome, Maternal morbidity, Perinatal mortality

\section{INTRODUCTION}

Hemolysis, elevated liver enzymes, and low platelets (HELLP) syndrome has been recognized as a complication of preeclampsia-eclampsia for decades. Recognition of this syndrome in women with preeclampsia is increasing because of the frequency of blood test results that reveal unexpected thrombocytopenia or elevated liver enzymes.

The diagnosis of HELLP syndrome requires the presence of haemolysis based on examination of the peripheral smear, elevated indirect bilirubin levels, increased serum
LDH level or low serum haptoglobin levels in association with significant elevation in liver enzymes and a platelet count below $100,000 / \mathrm{mm}^{3}$ after ruling out other causes of haemolysis and thrombocytopenia.

The incidence of HELLP syndrome is 10 to $20 \%$ while that of partial HELLP syndrome is unclear around 21 to $24 \% .^{1,2}$ In spite of delivery being the definitive treatment for women it worsens over the first 48 hours after delivery. ${ }^{3}$

The presence of this syndrome is associated with increased risk of adverse outcome for both mother and 
foetus. During the past 15 years, several retrospective and observational studies and a few randomized trials have been published in an attempt to refine the diagnostic criteria, to identify risk factors for adverse pregnancy outcome, and to treat women with this syndrome.

When platelet count decreases to less than 50,000/mm, disseminated intravascular coagulation (DIC) can occur, with a worse prognosis estimated at $19-27.0 \% .^{4}$ The purpose of this study is to analyse the maternal and perinatal outcome in patients of HELLP and partial HELLP complicating severe preeclampsia and eclampsia.

As with preeclampsia, the etiology and pathogenesis of HELLP syndrome is not completely understood. An increase in vascular thrombosis and activation of the coagulation system may be important in the clinicalpresentation of this disorder. Laboratory criteria for the diagnosis of HELLP syndrome have been classically described but lack of uniformity among different institutions. Aggressive management of HELLP syndrome with expeditious delivery appears to yield the lowest perinatal mortality rates. Conservative or expectant management has been associated with higher stillbirth rates with antenatal corticosteroids not causing resolution of the laboratory abnormalities. Resolution of laboratory abnormalities in HELLP syndrome runs a protracted course over several days after delivery. Despite nearly two decades since HELLP syndrome has been defined as a clinical entity, treatment for the disorder still remains delivery of the patient. ${ }^{5}$

In view of above we decided to undertake a study to explore the outcome of pregnancy in HELLP syndrome.

Aims and objectives of this study were to study maternal and perinatal outcome in hypertensive disorder of pregnancy complicated with HELLP and partial HELLP syndrome and to study the incidence of HELLP syndrome and partial HELLP syndrome in patient with severe pre-eclampsia and eclampsia.

\section{METHODS}

Present study was a prospective, observational and analytical study carried out in a tertiary care centre in 300 Women $>20$ weeks of gestation hospitalized for gestational hypertension. Duration of the study was 2 years

We studied all the patients who were admitted during pregnancy or and have a blood pressure elevation that is first detected after mid pregnancy i.e. after 20 weeks, either with proteinuria (preeclampsia) or without it (gestational hypertension) and/or with convulsions (eclampsia).

Patients were defined as having hypertension according to the criteria of national high blood pressure education programme.

\section{HELLP syndrome}

It is defined by the presence all 3 laboratory criteria proposed by Sibal in the Tennessee classification system ${ }^{5}$

- Hemolysis

a) Peripheral blood smear

b) Serum billirubin $>1.2 \mathrm{gm} / \mathrm{ml}$

c) Serum lactate dehydrogenase $600 \mathrm{UI} / \mathrm{I}$

- Elevated liver enzymes (serum aspartate transaminase or SGOT $70 \mathrm{U} / \mathrm{L})$

- $\quad$ Low platelet count $(<1,00,000 \mathrm{U} / \mathrm{L})$

Partial HELLP syndrome was defined by the presence of at least one or two features of HELLP syndrome but not complete syndrome

Gestational age was determined by reliable menstrual history; early clinical evaluation and ultrasonography at 20 weeks of gestation.

We evaluated the abnormal laboratory findings in the HELLP group and the partial HELLP group and the gestational age at which it was diagnosed.

\section{Inclusion criteria}

- Preeclampsia: minimum criteria 1) BP 140/90mmHg 20 weeks of gestation 2) proteinuria $>300$ for 24 hours or $1+$ dipstick

- Eclampsia: Seizures that cannot be attributed to any other causes in women with preeclampsia.

\section{Exclusion criteria}

- Chronic hypertension

- Liver disease

- Renal disease

- Hematological disease

\section{Outcome measures}

WE studied the incidence of HELLP syndrome and partial HELLP syndrome in patients with gestational hypertension, preeclampsia and eclampsia.

We analyzed the maternal outcome in patients of HELLP/partial HELLP with respect to parity, gestational age, classification of hypertensive disorders, gestational age at which diagnosis of hypertension is made, maternal complications (eclampsia, DIC, acute renal failure, placental abruption, cerebral hemorrhage, hypertensive encephalopathy, acute pulmonary edema, acute respiratory failure, severe sepsis) maternal mortality.

We analyzed the perinatal outcome in particular of HELLP and partial HELLP complicating gestation hypertension, preeclampsia and eclampsia. 


\section{RESULTS}

In present study incidence of HELLP and partial HELLP, maternal and perinatal outcome of HELLP and partial HELLP syndrome was studied in patients with severe preeclampsia and eclampsia.

\section{Incidence of HELLP and partial HELLP syndrome}

Out of 300 patients with preeclampsia 34 cases that is $11.33 \%$ patient had HELLP syndrome and 44 cases that is $14.66 \%$ patient had partial HELLP syndrome.

Table 1: Parity wise distribution.

\begin{tabular}{|llll|}
\hline $\begin{array}{l}\text { Parity } \\
\text { status }\end{array}$ & $\begin{array}{l}\text { Partial } \\
\text { HELLP }(\%)\end{array}$ & $\begin{array}{l}\text { HELLP } \\
(\%)\end{array}$ & $\begin{array}{l}\text { Chi } \\
\text { square } \\
\text { P value }\end{array}$ \\
\hline Primigravida & $26(59.09)$ & $29(85.2)$ & $\begin{array}{l}3.07 \\
0.079\end{array}$ \\
\hline Multigravida & $18(40.9)$ & $5(14.7)$ & $\begin{array}{l}4.78 \\
0.029\end{array}$ \\
\hline
\end{tabular}

Table 1 shows in present study most of the patient were primigravida i.e. $85.2 \%$ in HELLP and $59.09 \%$ in partial HELLP group. $\mathrm{P}$ value was highly significant in HELLP (0.029) while not significant in partial HELLP $\left(0.079^{`}\right)$.

Table 2: Gestation wise distribution.

\begin{tabular}{|ll|l|}
\hline $\begin{array}{l}\text { Gestational age } \\
\text { (weeks) }\end{array}$ & $\begin{array}{l}\text { Partial HELLP } \\
(\%)\end{array}$ & HELLP (\%) \\
\hline$<28$ & $2(4.5)$ & $2(5.8)$ \\
\hline $28-32$ & $10(22.7)$ & $7(20.7)$ \\
\hline $33-36$ & $8(18.18)$ & $13(38.23)$ \\
\hline$>36$ & $24(54.5)$ & $12(35.29)$ \\
\hline P value & 0.549 & 0.05 \\
\hline
\end{tabular}

Gestation age wise distribution of patients in the present study showed most patients with HELLP syndrome were between 33-36 weeks (38.2\%) and majority of patients in partial HELLP group were of gestation age $>36$ weeks $(54.5 \%)$. Both groups were studied statistically were significant correlation was seen with HELLP syndrome.

\section{Maternal complication}

Table shows various maternal complications in patients with HELLP and partial HELLP syndrome. Most common complication with in HELLP syndrome was DIC and an equal number of placental abruption, eclampsia and PPH most commonly in partial HELLP. Postpartum collapse, acute renal failure, intra cerebral haemorrhage and multi organ dysfunction syndrome were seen only in partial HELLP cases, not in HELLP syndrome. Both the groups were analyzed statistically using chi-square test, but difference was not statistically significant.
Table 3: Maternal complications.

\begin{tabular}{|llll|}
\hline Complications & $\begin{array}{l}\text { Total } \\
\text { cases }\end{array}$ & $\begin{array}{l}\text { Partial } \\
\text { HELLP (\%) }\end{array}$ & $\begin{array}{l}\text { HELLP } \\
(\%)\end{array}$ \\
\hline Placental abruption & 11 & $6(13.6)$ & $5(14.7)$ \\
\hline Eclampsia & 10 & $6(13.6)$ & $4(11.6)$ \\
\hline PPH & 11 & $6(13.6)$ & $5(14.7)$ \\
\hline Postpartum collapse & 3 & $3(6.8)$ & - \\
\hline Acute renal failure & 1 & $1(2.3)$ & \\
\hline DIC & 11 & $5(11.4)$ & $6(17.6)$ \\
\hline Sepsis & 4 & $2(4.5)$ & $2(5.8)$ \\
\hline $\begin{array}{l}\text { Intracerebral } \\
\text { haemorrhage }\end{array}$ & 1 & $1(2.3)$ & \\
\hline MODS & 2 & $2(4.5)$ & \\
\hline
\end{tabular}

\section{Perinatal mortality}

Perinatal mortality was seen in $6(17.6 \%)$ babies with HELLP syndrome of which $3(8.8 \%)$ were stillborn, $2(5.88 \%)$ died within 7 days and $1(2.9 \%)$ died after 7 days. While in patient with partial HELLP perinatal mortality was seen in $11(25 \%)$ babies. Of these 7 (15.9\%) were stillborn, $2(4.54 \%)$ died within 7 days and $2(4.54 \%)$ died after 7 days. Statistical significance was not found in both groups when analyzed by chi-square test.

Table 4: Perinatal mortality.

\begin{tabular}{|lllll|}
$\begin{array}{l}\text { Perinatal } \\
\text { outcome }\end{array}$ & $\begin{array}{l}\text { Stillborn } \\
(\%)\end{array}$ & $\begin{array}{l}\text { Death }<7 \\
\text { days }(\%)\end{array}$ & $\begin{array}{l}\text { Death }>7 \\
\text { days }(\%)\end{array}$ & $\begin{array}{l}\text { p- } \\
\text { value }\end{array}$ \\
\hline HELLP & $3(8.82)$ & $2(5.88)$ & $1(2.9)$ & 0.53 \\
\hline $\begin{array}{l}\text { Partial } \\
\text { HELLP }\end{array}$ & $7(15.9)$ & $2(4.54)$ & $2(4.54)$ & 0.205 \\
\hline
\end{tabular}

Table 5 shows various neonatal complications in HELLP and partial HELLP syndrome. In both the groups LBW (birth weight $<2.5 \mathrm{Kg}$ ) was the most common neonatal complication followed by preterm delivery. In HELLP NICU admission was seen for 6days (p-value 0.4374), whereas in partial HELLP it was 7 days ( $p$ value 0.5688 ). Statistical significance was tested by chi-square test which was not found significant.

Table 5: Neonatal complication.

\begin{tabular}{|lll|}
\hline & $\begin{array}{l}\text { Partial } \\
\text { HIELLP (\%) } \\
(44)\end{array}$ & $\begin{array}{l}\text { HIELCP (\%) } \\
(34)\end{array}$ \\
\hline LBW (Low birth weight) & $37(84.09)$ & $27(79.4)$ \\
\hline IUGR & $7(15.9)$ & $6(17.6)$ \\
\hline Sepsis & $1(2.3)$ & $1(2.9)$ \\
\hline IUD & $7(15.9)$ & $3(8.8)$ \\
\hline Preterm & $27(61.4)$ & $21(61.8)$ \\
\hline $\begin{array}{l}\text { Respiratory distress } \\
\text { syndrome }\end{array}$ & $3(6.8)$ & $1(2.9)$ \\
\hline
\end{tabular}




\section{Maternal mortality}

Maternal mortality occurred in one (2.9\%) patient with HELLP syndrome and cause of death was atonic postpartum haemorrhage with DIC and sepsis. In partial HELLP syndrome maternal mortality was seen in 2 (4.5\%) patients due to eclampsia with DIC, intracerebral haemorrhage, multiple organ dysfunction and hypertensive encephalopathy in one case. In the other patient cause was placental abruption with postpartum collapse and acute renal failure.

\section{DISCUSSION}

HELLP syndrome is an expression of severe preeclampsia and eclampsia with reported incidence ranging between $10-20 \% .{ }^{6,12}$ In the present study incidence of HELLP syndrome was found to be $11.33 \%$ and $14.66 \%$ for partial HELLP syndrome. Batucatu et al found the incidence of HELLP to be $12.9 \% .^{7}$ These were comparable to the present study while an Indian study by Chabbra S et al found it to be $23.58 \%$. Study by Tandon A et al found incidence of HELLP $1.7 \%$ and partial HELLP 7.3\%. ${ }^{9}$ The latter shows a decreasing trend. However, the difference in incidence is due to difference in patient characteristics and condition of each population

In the present study $14.7 \%$ patients of HELLP and $13.6 \%$ with partial HELLP developed abruption. Audibert et al found rate to be $9 \% .^{2}$ In the study by Tandonet $\mathrm{A}$ et al $12.35 \%$ patients with partial HELLP had abruption which was similar to the present study. ${ }^{9}$

In the present study eclampsia was seen in 5 patients $(14.7 \%)$ with HELLP and $6(13.6 \%)$ with partial HELLP. In Study by Tandonet A al $44.3 \%$ patients with HELLP and $31.46 \%$ with partial HELLP had eclampsia. ${ }^{9}$ In de Botucatu study on partial HELLP, eclampsia was found in $14.6 \%$ of patients which is comparable to our study. Risk of postpartum hemorrhage is increased in patient with HELLP syndrome 5 patients (14.7\%) and 6 (13.6\%) with partial HELLP had PPH in the present study. In study by Ahmed $\mathrm{N}$ et al $12.5 \%$ patient had PPH which is comparable to the present results. ${ }^{10}$ Postpartum collapse was seen in 3 (6.8\%)patients with partial HELLP and no patient with HELLP. Literature search did not reveal any other study reporting postpartum collapse.

Placental abruption and postpartum onset of HELLP syndrome increases risk of acute renal failure. In general, renal system morbidity increases as the disease status worsens. In the present study acute renal failure was seen in one patient $(2.3 \%)$ with partial HELLP and none with HELLP syndrome. The woman required hemodialysis. Selahattinet al found renal failure in $13.88 \%$ of patient and all needed dialysis. ${ }^{11}$

Activation of vascular endothelium and platelets, hemolysis and liver damage are the basic pathophysiological features characteristic for the HELLP syndrome and each predisposing to DIC. In the present study $17.6 \%$ patients with HELLP and $11.4 \%$ patients with partial HELLP had DIC. Audibertet al reported DIC in $15 \%$ while Banoo $\mathrm{S}$ et al noted DIC in $10 \%$ patient. ${ }^{2,12}$ In a large retrospective study by Sibai BM et al $38 \%$ patient with HELLP had DIC and most often related to placental abruption. ${ }^{13}$ Abruptio placentae associated with HELLP syndrome increases the risk of DIC and need for blood transfusion.

Patient with HELLP syndrome more often develop infectious morbidity compared to those with severe preeclampsia without HELLP. Sepsis was seen in 5.8\% patients with HELLP and $4.5 \%$ patients with partial HELLP syndrome. Sibai BM et al and Martin JN et al reported $43 \%$ infection rate in HELLP as compared to $20 \%$ in non HELLP. ${ }^{3,13}$ Abdominal delivery doubles the infectious morbidity from $19 \%$ to $41 \%$ as reported by Martin JN et al. ${ }^{3}$ Tandonet $\mathrm{A}$ al found sepsis in $5.6 \%$ patients with partial HELLP. ${ }^{9}$

In the literature there are several case reports on cerebral bleeding associated with the HELLP syndrome. In the present study only one patient with partial HELLP syndrome suffered from intracerebral haemorrhage and hypertensive encephalopathy. In a report by Sibaiet al on outcome of 442 patient of HELLP, there was no mention of cerebral bleeding as a complication. ${ }^{13}$ Audibertet al report cerebral bleeding in $1.5 \%$ patients. $^{2}$ The risk of stroke is often not increased during pregnancy itself but witnessed some weeks after delivery.

Present study does not report any case of hepatic failure or liver hematoma. Spontaneous rupture of a subcapsular liver hematoma is a rare, but life-threatening complication that occurs 1 in 40,000 to 1 in 250,000 deliveries and about 1 to $<2 \%$ of cases with HELLP syndrome. Rupture most often occurs in the right lobe. ${ }^{14,15}$ The symptoms are sudden onset of severe pain in the epigastric and right upper quadrant radiating to the back and right shoulder, anemia and hypotension. The condition may be diagnosed by ultrasound, CT or MRI. Hepatic rupture may also occur in the post-partum period.

Risk of developing pulmonary edema and ARDS is doubled in patient with HELLP syndrome as compared to severe preeclampsia. Audibert et al and Martin JN et al reported $8 \%$ cases of pulmonary edema and $<1 \%$ incidence of ARDS. ${ }^{2,3}$ There were no cases of pulmonary edema or ARDS in the present study.

There were 2 (4.5\%) cases of partial HELLP syndrome in the present study who developed multiple organ dysfunction (MOD) and which ended fatally. In study by Tandon A et al MOD was seen in $8.1 \%$ patients with HELLP and $6.7 \%$ patients with partial HELLP. ${ }^{9}$ Maternal mortality occurred in one $(2.9 \%)$ patient with HELLP syndrome and cause of death was atonic postpartum hemorrhage with DIC with sepsis. In partial HELLP syndrome maternal mortality was seen in $2(4.5 \%)$ 
patients. Cause of death in one patient was eclampsia with DIC, intracerebral hemorrhage hypertensive encephalopathy and ultimately multiple organ dysfunction. In the other patient cause was placental abruption, postpartum collapse with acute renal failure. In Selahattin et al study maternal death was seen in only one case $(4.5 \%)$ out of 22 HELLP syndrome cases. ${ }^{11}$

Present study demonstrated neonatal morbidity increased significantly among HELLP and partial HELLP syndrome. Babies with partial HELLP showed significant risk of low birth weight. In the present study $84 \%$ infants in partial HELLP and $79 \%$ with HELLP were low birth weight $(<2.5 \mathrm{~kg})$. The mean birth weight was $1088 \mathrm{gm}$. Mean birth weight found by Sibaiet al was $1527 \mathrm{gm}$ and 1371.5 gm by Beller et al. ${ }^{13,16}$ Only one $(2.9 \%)$ baby with HELLP and one $(2.3 \%)$ with partial HELLP had sepsis. $61 \%$ of babies with HELLP or partial HELLP were preterm in the present study. In the Botucatu's study on partial HELLP, preterm deliveries were $70.7 \%$ and IUGR was seen in $26.8 \%$ babies. $^{7}$ In the present study $3(6.8 \%)$ babies in partial HELLP group had RDS while in HELLP one $(2.9 \%)$ baby had RDS. Most common cause of morbidity was LBW and prematurity. In the study by Weinstein perinatal mortality occurred in $7.9 \%$ of infants. ${ }^{17}$ Perinatal mortality and morbidity are considerably higher in HELLP syndrome and are primarily dependent on gestational age. The perinatal mortality rate related to HELLP syndrome is between $7.4 \%$ and $34 \% .^{18}$ Neonatal thrombocytopenia occurs in between $15 \%$ and $38 \%$ cases and is significant risk factor for both intraventricular hemorrhage and long term neurological complication. ${ }^{18}$

In the present study neonatal mortality was seen in $17.64 \%$ babies with HELLP syndrome $25 \%$ with partial HELLP syndrome which is comparable to above studies. When perinatal results were evaluated in Selahattin et al study, it was found that HELLP syndrome cases had six times more risk of neonatal mortality than severe preeclampsia cases even though it was statistically not significant. ${ }^{11}$ Additionally, it was observed that other perinatal problems were more in HELLP syndrome cases, but again statistically insignificant. Evidence has substantiated the fact that prematurity per se is the main reason of increased neonatal mortality in HELLP syndrome rather than HELLP syndrome itself. Haddad et al reported that HELLP syndrome and pre-eclamptics have similar neonatal mortality when compared with general mortality of newborns of similar gestational age. ${ }^{19}$ Gestational age mainly contributes to the increase tendency of perinatal morbidity and mortality observed in HELLP syndrome.

In other studies, it has been seen that perinatal mortality and morbidity is considerably higher in HELLP syndrome and it is dependent mainly on gestation age. Gulet al showed $34 \%$ mortality before 32 weeks gestation and $8 \%$ after 32 weeks of gestation. ${ }^{18}$ Prematurity, placental insufficiency, intrauterine growth retardation and abruptio placentae, are leading cause of perinatal mortality

\section{CONCLUSION}

The aim of this study was to determine the incidence and maternal and fetal outcome of HELLP and partial HELLP syndrome. Widespread recognition and earlier diagnosis of HELLP syndrome as a variant of severe preeclampsia have led to an improvement in maternal and perinatal outcome. Unfortunately, the only cure for HELLP syndrome is delivery, even at early gestational ages. Further advancement in prevention and possibly treatment of the disorder will rest upon a more complete understanding of the etiology and pathogenesis of preeclampsia. At this time, the clinician is advised to consider aggressive management with expeditious delivery when treating a patient with HELLP syndrome.

\section{Funding: No funding sources}

Conflict of interest: None declared

Ethical approval: The study was approved by the Institutional Ethics Committee

\section{REFERENCES}

1. Haram K, Svendsen E, Abildgaard U. The HELLP syndrome: clinical issues and management: a review. BMC Pregnancy Childbirth. 2009;9:8.

2. Audibert F, Friedman SA, Frangieh AY, Sibai BM. Clinical utility of strict diagnostic criteria for the HELLP (hemolysis, elevated liver enzymes, and low platelets) syndrome. Am J Obstet Gynecol.1996;175:460-4.

3. Martin JN, Jr, Rose CH, Briery CM. Understanding and managing HELLP syndrome: the integral role of aggressive glucocorticoids for mother and child. Am J Obstet Gynecol. 2006;195:914-34.

4. Abramovici D, Friedman SA, Mercer BM, Audibert F, Kao L,Sibai BM. Neonatal outcome in severe preeclampsia at 24 to 36 weeks' gestation: Does the HELLP (hemolysis, elevated liver enzymes, and low platelet count) syndrome matter? Am J Obstet Gynecol. 1999;180:221-5.

5. Barton JR, Sibai BM. Diagnosis and management of hemolysis, elevated liver enzymes, and low platelets syndrome. Clin Perinatol. 2004;31:807-33.

6. Pritchard JA, Cunningham FG, Masan RA. Coagulation changes in eclampsia; their frequency and pathogenesis. Am J Obst Gynaecol. 1976; $124: 855$.

7. Abbade JF, Peraçoli JC, Costa RA, Calderon ID, Borges VT, Rudge MV. Partial HELLP syndrome: maternal and perinatal outcome. Sao Paulo Med J. 2002;120(6):180-4.

8. Chhabra S, Qureshi A, Datta N. Perinatal outcome with HELLP/partial HELLP complicating hypertensive disorders of pregnancy: an Indian rural experience. J Obstet Gynaecol. 2006;26(6):531-3. 
9. Tandon A, Chaudhari P, Gupta V, Ramola M. Fetomaternal outcome in HELLP and partial HELLP syndrome. Int J Reprod Contracept Obstet Gynecol. 2016;5(9):3066-71.

10. Ahmed FA, Amin A, Naeem NK. HELLP syndrome, a clinical variant of pre-eclampsia. Annals. 2007;13(2):158

11. Kumru S, Güretaş MSB, Sapmaz E, Aygün D. Comparison of maternal and perinatal outcomes of HELLP syndrome and severe preeclampsia cases. Perinatal J. 2005;13(1):9-14.

12. Banoo S, Makhdoomi TA, Mir S, Malik J. Incidence of HELLP syndrome and its effect on maternal and perinatal outcome. JK Practitioner. 2007;14(2):92-4.

13. Sibai BM, Ramadan MK, Usta I, Salama M, Mercer BM, Friedman SA. Maternal morbidity and mortality in 442 pregnancies with hemolysis, elevated liver enzymes, and low platelets (HELLP syndrome). Am J Obstet Gynecol. 1993;169:1000-06.

14. Aarnoudse JG, Houthoff HJ, Weits J, Vellenga E, Huisjes HJ. A syndrome of liver damage and intravascular coagulation in the last trimester of normotensive pregnancy. A clinical and histopathological study. $\mathrm{Br} \mathrm{J}$ Obstet Gynaecol. 1986;93:145-55.

15. Minakami H, Oka N, Sato T, Tamada T, Yasuda Y, Hirota N. Preeclampsia: a microvesicular fat disease of the liver?. Am J Obstet Gynecol. 159:1043-7.
16. Beller FK, Dame WR, Ebert C. Pregnancy induced hypertension complicated by thrombocytopenia hemolysis and elevated liver enzymes (HELLP) syndrome: renal biopsies and outcome. Au Nz J Obst Gynecol. 1985;25:83.

17. Weinstein L. Syndrome of hemolysis, elevated liver enzymes and low platelet count: a severe consequence of hypertension in pregnancy. Am J Obst Gynecol. 1382;142:159

18. Gul A, Cebeci A, Aslan H, Polat I, Ozdemir A, Ceylan Y. Perinatal outcomes in severe preeclampsia-eclampsia with and without HELLP syndrome. Gynecol Obstet Invest. 2005;59:113-8.

19. Hadded B, Barton JR, Livingston JC, Chahine R, Sibai BM. Risk factors for adverse maternal outcome among women with HELLP syndrome. Am J Obstet Gynecol. 2000;183:444-8.

Cite this article as: Durugkar K, Bal H, Agrawal S. A study of maternal and perinatal outcome in cases of HELLP and partial HELLP syndrome. Int J Reprod Contracept Obstet Gynecol 2017;6:5491-6. 